\title{
Relationship between final adult height and birth weight after gonadotropin-releasing hormone agonist treatment in girls with central precocious puberty
}

\author{
Ah Young Cho, MD, \\ Su Yeong Ko, MD, \\ Jae Hee Lee, MD, \\ Eun Young Kim, MD
}

Department of Pediatrics, Chosun University Hospital, Gwangju, Korea
Received: 4 July, 2019

Revised: 22 August, 2019

Accepted: 2 September, 2019

Address for correspondence:

Eun Young Kim, MD

Department of Pediatrics, Chosun University Hostpital, 365 Pilmundaero, Dong-gu, Gwangju 61453, Korea

Tel: +82-62-220-3050

Fax: +82-62-227-2904

E-mail: sskey@chosun.ac.kr https://orcid.org/0000-0002-30735222
Purpose: The clinical significance of birth weight relative to gestational age in girls with central precocious puberty is unclear. This study sought to compare clinical parameters such as final adult height (FAH) and menarche onset after treatment with gonadotropin-releasing hormone agonist $(\mathrm{GnRHa})$ on birth weight in girls with central precocious puberty treated.

Methods: This retrospective study reviewed data of $69 \mathrm{girls}$ with precocious puberty who had reached their FAH in a long-term trial of GnRHa treatment between January 2007 and December 2017. The subjects were divided into small for gestational age (SGA) $(n=19)$ and appropriate for gestational age (AGA) $(n=50)$ groups.

Results: When starting GnRHa treatment, bone age was $10.9 \pm 0.9$ and $10.3 \pm 0.8$ years in the SGA and AGA groups, respectively $(P<0.05)$. The predicted adult height (PAH) (established according to the Bayley-Pinneau average table) and advanced PAH (established according to the Bayley-Pinneau advanced table) were $151.5 \pm 4.8 \mathrm{~cm}$ and $155.8 \pm 4.9 \mathrm{~cm}$ in the SGA group, respectively, and $153.4 \pm 5.3 \mathrm{~cm}$ and $159.0 \pm 6.0$ $\mathrm{cm}$ in the AGA group. After treatment, no significant difference in bone age was found between the groups. The time to menarche after treatment was $12.5 \pm 7.6$ and $21.1 \pm 12.3$ months in the SGA and AGA groups, respectively $(P<0.05)$. FAH in the SGA and AGA groups was $161.0 \pm 4.7 \mathrm{~cm}$ and $161.6 \pm 5.0 \mathrm{~cm}$, respectively, without a significant difference.

Conclusion: SGA girls with precocious puberty have increased bone age and earlier menarche relative to AGA girls. However, no difference in FAH after treatment was found between these groups.

Keywords: Precocious puberty, Gonadotropin-releasing hormone, Birth weight

\section{Introduction}

Central precocious puberty is a condition when secondary sexual characteristics are observed in girls younger than the age of eight years and in boys younger than the age of 9 years due to early activation of the hypothalamus-pituitary-gonadal axis. ${ }^{1)}$ Increased gonadal hormonal secretion promotes bone maturation, which leads to early epiphyseal fusion and a shorter final adult height $(\mathrm{FAH}){ }^{2)}$ To prevent this, gonadotropin-releasing hormone agonist (GnRHa) can be used to suppress secretion of gonadal hormones and delay early bone maturation and menarche, facilitating an increased $\mathrm{FAH}^{3}{ }^{3)}$

Many studies have investigated the factors associated with FAH after treatment with GnRHa (GnRHa treatment) in central precocious puberty, which include chronological age, height, target height $(\mathrm{TH})$, and predicted adult height $(\mathrm{PAH})$ at the start of treatment; duration of treatment; and PAH at the end of the treatment. ${ }^{4,5)}$ However, very few studies to date have 
considered the clinical significance of birth weight relative to gestational age in children with central precocious puberty. In general, although the exact frequency differs depending on geographic region, approximately $2.3 \%$ to $10 \%$ of all newborns are born at small for gestational age (SGA) - that is, below the 10th percentile of birth weight corresponding to gestational age. ${ }^{6}$ In SGA babies, growth in the first 2 years of life is very important, and most achieve catch-up growth. However, some previous studies have suggested that $10 \%$ to $20 \%$ of SGA babies fail to achieve catch-up growth within 2 to 3 years of birth and continue to be shorter than their appropriate for gestational age (AGA) peers. ${ }^{7,8)}$ Moreover, SGA babies show relatively faster bone maturation and growth rates, exhibit secondary sexual characteristics earlier, and experience menarche 5 to 10 months earlier than AGA babies. ${ }^{9,10)}$ In contrast, other studies have reported that age at onset of puberty, pubertal growth rate, and age at menarche do not differ between SGA and AGA children. $^{11,12)}$

Therefore, this study aimed to classify girls diagnosed with central precocious puberty according to birth weight and to compare clinical parameters such as FAH and its relationship with onset of menarche after GnRHa.

\section{Materials and methods}

\section{Patients and data collection}

This retrospective study identified 130 girls who were diagnosed and treated for central precocious puberty at the Department of Pediatrics at Chosun University Hospital between January 2007 and December 2017. Of these 130 girls, 69 who reached their FAH after GnRHa treatment and whose timing of menarche could be confirmed were included in the final analysis, which was conducted retrospectively based on medical records.

\section{Methods}

Diagnostic criteria for idiopathic central precocious puberty were (1) breast enlargement before eight years of age and (2) luteinizing hormone (LH) level (cutoff $\geq 5 \mathrm{IU} / \mathrm{L}$ ) in the $\mathrm{GnRH}$ stimulation test. We excluded girls with brain tumor and ovarian or adrenal lesion. In addition, thyroxine and thyroid-stimulating hormone (TSH) levels were measured in all patients to exclude hyperthyroidism.

Gestational age, birth weight, and height of parents were confirmed upon the initial visit in all patients. At the start of GnRHa treatment, 6 months into the treatment, and at end of the treatment, the following variables were measured: chronological age (CA), bone age (BA), height, body weight, body mass index (BMI), standard deviation scores (SDS) for height, body weight, and BMI relative to CA; peak LH/folliclestimulating hormone (FSH) ratio at the start of treatment, basal LH/FSH ratio at 6 months after treatment and at end of the treatment, TSH level, and free T4 level. FAH was measured when patients achieved a BA of 15 years or when the growth rate was less than $1 \mathrm{~cm} / \mathrm{yr}$. The time between the end of $\mathrm{GnRHa}$ treatment and menarche was also confirmed.

BA was measured using the Greulich-Pyle method on plain radiographs of the left hand and wrist, ${ }^{13)}$ and TH was defined as the average of parental heights minus $6.5 \mathrm{~cm}$. BayleyPinneau (BP) average tables were used to measure $\mathrm{PAH}$, and BP advanced tables were used to measure PAHa. ${ }^{14)}$

Leuprolide acetate was administered every 28 days at a dose of $60 \mu \mathrm{g} / \mathrm{kg}$ in girls. To determine the SDS (standard deviation score) of physical development, the standard pediatric growth table published by the Korean Pediatric Society in 2007 was used. SGA was defined as birth weight below the 10th percentile of birth weight corresponding to gestational age; of the 69 participants, 19 were placed in the SGA group. AGA was defined as birth weight between the 10th and 90th percentiles of birth weight corresponding to gestational age; of the 69 participants, 50 were placed in the AGA group. No patient was born large for gestational age.

\section{Statistical analysis}

The IBM SPSS Statistics ver. 24.0 (IBM Co., Armonk, NY, USA) was used for statistical analysis. Data were presented as mean \pm standard deviation. The significance of differences between the means of clinical variables according to timing of measurement during treatment in all patients was tested through paired $t$-tests. The Mann-Whitney $U$-test, which is a nonparametric test, was used to investigate differences and significance of differences in clinical factors between AGA $(\mathrm{n}=50)$ and SGA $(\mathrm{n}=19)$ groups. In 2 -sided tests, $P<0.05$ was set as the level of statistical significance. Simple and multiple linear regressions were used to investigate the relationship between clinical factors that may influence FAH after GnRHa treatment.

\section{Results}

\section{Auxological and clinical characteristics of girls with idiopathic CPP (central precocious puberty) according to timing of measurement during $\mathrm{GnRHa}$ treatment}

Clinical variables of all 69 patients measured at the start of GnRHa treatment are shown in Table 1.

At the start of GnRHa treatment, the CA was $8.6 \pm 0.8$ years and the BA was $10.4 \pm 0.9$ years. At 6 months into GnRHa treatment, the CA was $9.0 \pm 0.8$ years and $\mathrm{BA}$ was $11.0 \pm 0.9$ years. Finally, at the end of GnRHa treatment, the CA was $10.8 \pm 0.6$ years and the BA was $12.1 \pm 0.4$ years. The $\mathrm{TH}$ of all 69 patients was $159.3 \pm 3.8 \mathrm{~cm}$, while the FAH after GnRHa treatment was $161.5 \pm 4.6 \mathrm{~cm}$. Further, the mean duration of GnRHa treatment for all patients was $27.5 \pm 12.2$ months, and the patients reached menarche $19.5 \pm 11.8$ months after GnRHa treatment. 
Table 1. Auxological and clinical characteristics in 69 central precocious puberty girls $(n=69)$

\begin{tabular}{|c|c|c|c|c|}
\hline Variable & At start of $\mathrm{GnRHa}$ & At 6 months after treatment & At end of treatment & At adult height \\
\hline$\overline{C A}(\mathrm{yr})$ & $8.6 \pm 0.8$ & $9.0 \pm 0.8$ & $10.8 \pm 0.6^{*, t}$ & $16.2 \pm 0.4^{*,+, \neq}$ \\
\hline $\mathrm{BA}(\mathrm{yr})$ & $10.4 \pm 0.9$ & $11.0 \pm 0.9^{*}$ & $12.1 \pm 0.4^{*, \dagger}$ & - \\
\hline $\mathrm{BA} / \mathrm{CA}$ & $1.2 \pm 0.1$ & $1.2 \pm 0.1$ & $1.1 \pm 0.1^{*,+}$ & - \\
\hline Height $(\mathrm{cm})$ & $133.5 \pm 6.0$ & $137.2 \pm 6.1^{*}$ & $145.7 \pm 4.1^{*,+}$ & $161.5 \pm 4.6^{*, t, \pm}$ \\
\hline Height SDS & $0.4 \pm 0.9$ & $0.8 \pm 0.9^{*}$ & $0.4 \pm 0.9^{\dagger}$ & $0.4 \pm 0.9^{t, \neq}$ \\
\hline $\mathrm{PAH}(\mathrm{cm})$ & $153.1 \pm 5.2$ & $153.7 \pm 5.1^{*}$ & $157.6 \pm 4.7^{*,+}$ & - \\
\hline PAHa $(\mathrm{cm})$ & $157.9 \pm 6.9$ & $158.5 \pm 5.5$ & $161.2 \pm 4.9^{*, t}$ & - \\
\hline BMI $\left(\mathrm{kg} / \mathrm{m}^{2}\right)$ & $17.5 \pm 2.6$ & $17.7 \pm 2.0$ & $19.2 \pm 2.4^{*, t}$ & $22.1 \pm 2.1^{*,+, \neq}$ \\
\hline BMI SDS & $0.2 \pm 0.9$ & $0.3 \pm 0.8$ & $0.3 \pm 0.9^{*}$ & $0.4 \pm 0.8$ \\
\hline LH/FSH & $1.0 \pm 0.8$ & $0.2 \pm 0.1^{*}$ & $0.8 \pm 1.6$ & - \\
\hline TSH & $3.3 \pm 2.1$ & $2.8 \pm 1.6$ & $1.9 \pm 0.8$ & - \\
\hline Free T4 & $1.3 \pm 0.3$ & $1.3 \pm 0.3$ & $1.2 \pm 0.2$ & - \\
\hline Birth weight $(\mathrm{kg})$ & $3.1 \pm 0.6$ & - & - & - \\
\hline Duration of $\mathrm{GnRHa}$ & - & - & $27.5 \pm 12.2$ & - \\
\hline Time of menarche after treatment (mo) & - & - & - & $19.5 \pm 11.8$ \\
\hline Age of menarch (yr) & - & - & - & $12.47 \pm 1.21$ \\
\hline $\mathrm{TH}(\mathrm{cm})$ & $159.3 \pm 3.8$ & - & - & - \\
\hline
\end{tabular}

Values are presented as mean \pm standard deviation.

GnRHa, gonadotropin-releasing hormone agonist; CA, chronological age; BA, bone age; SDS, standard deviation score; PAH, predicted adult height-according to Baley-Pinneau's average table; PAHa, Predicted adult height-according to Baley-Pinneau's advanced table; BMI, body mass index; LH, luteinizing hormone; FSH, follicular stimulating hormone; TSH, thyroid-stimulating hormone; TH, target height.

${ }^{*} P<0.05$ compared with start of treatment. ${ }^{\dagger} P<0.05$ compared with 6 months after treatment. ${ }^{\ddagger} P<0.05$ compared with end of treatment
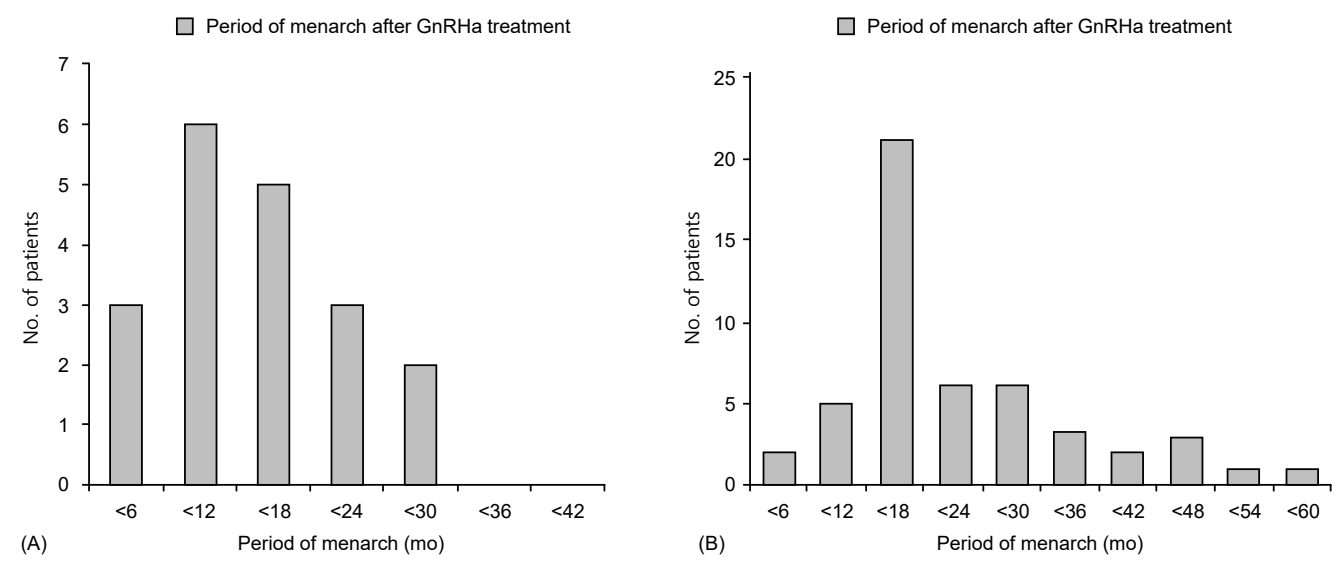

Fig. 1. (A) Period of menarch after GnRHa treatment in SGA group. (B) Period of menarch after GnRHa treatment in AGA group. GnRHa, gonadotropin-releasing hormone agonist; SGA, small for gestational age; AGA, appropriate for gestational age.

\section{Comparison of auxological and clinical characteristics between the SGA and AGA groups according to timing of measurement during GnRHa treatment}

We compared the results of clinical data and laboratory testing between the SGA and AGA groups (Table 2). Regarding the $\mathrm{BA}$ when starting the treatment, the mean values were $10.9 \pm 0.9$ and $10.3 \pm 0.8$ years in the SGA and AGA groups, respectively. The difference between $\mathrm{BA}$ and $\mathrm{CA}$ at the start of treatment was $2.2 \pm 0.4$ and $1.8 \pm 0.7$ years in the SGA and AGA groups, respectively; therefore, the BA was significantly more advanced in the SGA group $(P<0.05)$. Separately, the peak LH/FSH ratio was $1.5 \pm 1.4$ in the SGA group and $1.0 \pm 0.7$ in the AGA group, with no significant difference. The PAH was $151.5 \pm 4.8 \mathrm{~cm}$ in the SGA group and $153.4 \pm 5.3 \mathrm{~cm}$ in the AGA group; although the PAH was smaller in the SGA group, the difference was not significant. Conversely, the PAHa was $155.8 \pm 4.9 \mathrm{~cm}$ in the SGA group and $159.0 \pm 6.0 \mathrm{~cm}$ in the AGA group, a significant difference $(P<0.05)$ (Table 2$)$.

At 6 months into GnRHa treatment, there was no significant difference in any of the factors between SGA and AGA groups. Similarly, at the end of GnRHa treatment, the BA and the difference between BA and CA did not differ significantly between both groups; however, the BMI was $19.4 \pm 2.4$ in the 
SGA group and 17.9 \pm 2.1 in the AGA group, and the difference was significant $(P<0.05$, Table 2$)$.

The total duration of GnRHa treatment was $24.3 \pm 13.5$ months in the SGA group and $26.9 \pm 11.7$ months in the AGA group, showing a non-significant difference (Table 2). The time until menarche from the end of GnRHa treatment was $12.5 \pm 7.6$ months in the SGA group and 21.1 \pm 12.3 months in the AGA group; this time period was significantly shorter in the SGA group $(P<0.05)$ (Table 2; Fig. 1A, B). The FAH after GnRHa treatment was $161.0 \pm 4.7 \mathrm{~cm}$ in the SGA group and $161.6 \pm 5.0$ $\mathrm{cm}$ in the AGA group, with no significant difference, while the FAH was greater in both groups than the THs of $159.6 \pm 4.1 \mathrm{~cm}$

Table 2. Comparisons of auxological and clinical characteristics between SGA and AGA groups

\begin{tabular}{|c|c|c|c|}
\hline Variable & SGA $(n=19)$ & AGA $(n=50)$ & $P$-value \\
\hline \multicolumn{4}{|l|}{ At start of treatment } \\
\hline Birth weight (kg) & $2.5 \pm 0.5$ & $3.3 \pm 0.3$ & $<0.05$ \\
\hline $\mathrm{TH}(\mathrm{cm})$ & $159.6 \pm 4.1$ & $159.1 \pm 3.8$ & 0.509 \\
\hline$C A(y r)$ & $8.7 \pm 0.8$ & $8.5 \pm 0.8$ & 0.137 \\
\hline$B A(y r)$ & $10.9 \pm 0.9$ & $10.3 \pm 0.8$ & $<0.05$ \\
\hline $\mathrm{BA} / \mathrm{CA}$ & $1.2 \pm 0.1$ & $1.2 \pm 0.1$ & 0.096 \\
\hline$B A-C A(y r)$ & $2.2 \pm 0.4$ & $1.8 \pm 0.7$ & $<0.05$ \\
\hline Height (cm) & $135.8 \pm 6.8$ & $133.3 \pm 5.6$ & 0.301 \\
\hline Height SDS & $0.5 \pm 0.9$ & $0.5 \pm 1.0$ & 0.872 \\
\hline $\mathrm{PAH}(\mathrm{cm})$ & $151.5 \pm 4.8$ & $153.4 \pm 5.3$ & 0.077 \\
\hline $\mathrm{PAHa}(\mathrm{cm})$ & $155.8 \pm 4.9$ & $159.0 \pm 6.0$ & $<0.05$ \\
\hline $\mathrm{BMI}\left(\mathrm{kg} / \mathrm{m}^{2}\right)$ & $17.4 \pm 2.3$ & $17.8 \pm 2.8$ & 0.727 \\
\hline BMI SDS & $0.3 \pm 1.0$ & $0.3 \pm 0.9$ & 0.778 \\
\hline LH/FSH & $1.5 \pm 1.4$ & $1.0 \pm 0.7$ & 0.271 \\
\hline \multicolumn{4}{|l|}{ At 6 months after $\mathrm{GnRHa}$ treatment } \\
\hline$C A(y r)$ & $9.2 \pm 0.8$ & $9.0 \pm 0.8$ & 0.137 \\
\hline$B A(y r)$ & $11.4 \pm 0.9$ & $11.0 \pm 0.9$ & 0.096 \\
\hline $\mathrm{BA} / \mathrm{CA}$ & $1.2 \pm 0.1$ & $1.2 \pm 0.1$ & 0.357 \\
\hline$B A-C A(y r)$ & $2.2 \pm 0.4$ & $2.0 \pm 0.8$ & 0.154 \\
\hline Height (cm) & $138.3 \pm 7.1$ & $137.2 \pm 5.8$ & 0.925 \\
\hline Height SDS & $0.8 \pm 0.8$ & $0.9 \pm 0.9$ & 0.493 \\
\hline PAH (cm) & $153.0 \pm 5.8$ & $153.8 \pm 5.1$ & 0.207 \\
\hline PAHa (cm) & $157.2 \pm 5.9$ & $158.6 \pm 5.1$ & 0.173 \\
\hline $\mathrm{BMI}\left(\mathrm{kg} / \mathrm{m}^{2}\right)$ & $18.2 \pm 2.2$ & $17.8 \pm 2.8$ & 0.320 \\
\hline BMI SDS & $0.4 \pm 0.8$ & $0.3 \pm 0.9$ & 0.610 \\
\hline LH/FSH & $0.2 \pm 0.2$ & $0.1 \pm 0.1$ & 0.470 \\
\hline \multicolumn{4}{|l|}{ At end of GnRHa treatment } \\
\hline CA (yr) & $10.6 \pm 0.5$ & $10.7 \pm 0.7$ & 0.480 \\
\hline$B A(y r)$ & $12.1 \pm 0.5$ & $12.1 \pm 0.4$ & 0.808 \\
\hline $\mathrm{BA} / \mathrm{CA}$ & $1.1 \pm 0.1$ & $1.1 \pm 0.1$ & 0.528 \\
\hline$B A-C A(y r)$ & $1.5 \pm 0.7$ & $1.4 \pm 0.9$ & 0.493 \\
\hline Height (cm) & $144.0 \pm 4.4$ & $146.2 \pm 4.2$ & 0.081 \\
\hline Height SDS & $0.4 \pm 0.9$ & $0.5 \pm 1.0$ & 0.851 \\
\hline $\mathrm{PAH}(\mathrm{cm})$ & $156.0 \pm 5.1$ & $157.9 \pm 5.0$ & 0.164 \\
\hline PAHa (cm) & $159.5 \pm 5.4$ & $161.4 \pm 5.2$ & 0.200 \\
\hline $\mathrm{BMI}\left(\mathrm{kg} / \mathrm{m}^{2}\right)$ & $19.4 \pm 2.4$ & $17.9 \pm 2.1$ & $<0.05$ \\
\hline BMI SDS & $0.5 \pm 0.9$ & $0.3 \pm 0.8$ & 0.375 \\
\hline Duration of treatment (mo) & $24.3 \pm 13.5$ & $26.9 \pm 11.7$ & 0.307 \\
\hline Time of menarche after $\mathrm{GnRHa}$ (mo) & $12.5 \pm 7.6$ & $21.1 \pm 12.3$ & $<0.05$ \\
\hline Age of menarch (yr) & $11.87 \pm 1.17$ & $12.53 \pm 1.15$ & $<0.05$ \\
\hline $\mathrm{LH} / \mathrm{FSH}$ & $0.4 \pm 0.4$ & $1.0 \pm 1.8$ & 0.730 \\
\hline $\mathrm{FAH}(\mathrm{cm})$ & $161.0 \pm 4.7$ & $161.6 \pm 5.0$ & 0.500 \\
\hline
\end{tabular}

Values are presented as mean \pm standard deviation.

SGA, small for gestational age; AGA, appropriate for gestational age; GnRHa, gonadotropin-releasing hormone agonist; TH, target height; CA, chronological age; BA, bone age; PAH, predicted adult height-according to Baley-Pinneau's average table; PAHa, Predicted adult height-according to Baley-Pinneau's advanced table; BMI, body mass index; SDS, standard deviation score; LH, luteinizing hormone; FSH, follicular stimulating hormone; TSH, thyroid-stimulating hormone; FAH, Final adult height. 
in the SGA group and $159.1 \pm 3.8 \mathrm{~cm}$ in the AGA group (Table 2).

\section{Relationships between PAH, PAHa, and FH according to timing of measurement during treatment}

At the start of GnRHa treatment, the PAH and PAHa were $153.1 \pm 5.2 \mathrm{~cm}$ and $157.9 \pm 6.9 \mathrm{~cm}$, respectively. Although these were smaller than the TH of $159.8 \pm 3.8 \mathrm{~cm}$, they both increased over the course of GnRHa treatment. At 6 months into GnRHa treatment, the PAH was $153.7 \pm 5.1 \mathrm{~cm}$ and the PAHa was $158.5 \pm 5.5 \mathrm{~cm}$, and both values were higher than the baseline values. After GnRHa treatment, the PAH was $157.6 \pm 4.7 \mathrm{~cm}$, and the PAHa was $161.2 \pm 4.9 \mathrm{~cm}$; thus, both increased significantly compared to their baseline values $(P<0.05)$ (Table 1, Fig. 2).

The FAH in all patients was $161 \pm 4.6 \mathrm{~cm}$, which was greater than the TH of $159.3 \pm 3.8 \mathrm{~cm}$. Meanwhile, the FAH after GnRHa treatment was $161 \pm 4.6 \mathrm{~cm}$, similar to the PAHa measured using the BP advanced table (Fig. 2).

\section{Clinical factors influencing the FAH}

At the start of GnRHa treatment, the TH, height SDS, and PAHa had significant positive correlations with the FAH $(\beta=0.247, \beta=0.382$, and $\beta=0.288 ; P<0.05)$. However, at 6 months into GnRHa treatment, only the height SDS was significantly correlated with the FAH $(\beta=0.561, P<0.05)$. After GnRHa treatment, the height and height SDS showed significant positive correlations with the FAH $(\beta=0.537$ and $\beta=0.225 ; P<0.05)$ (Table 3).

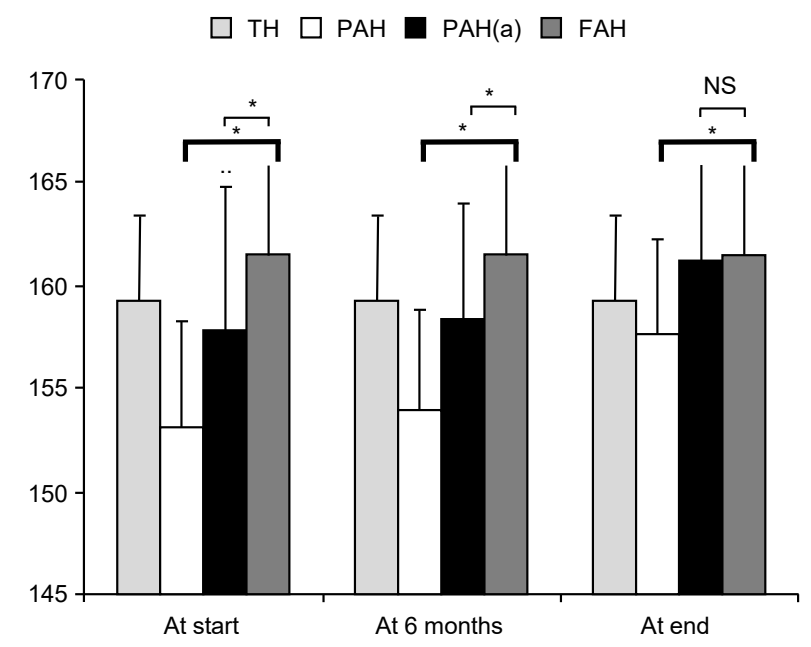

Fig. 2. Changes of $P A H, P A H a$, and FAH during GnRHa treatment. TH, target height; GnRHa, gonadotropin-releasing hormone agonist; $\mathrm{PAH}$, predicted adult height-according to Baley-Pinneau's average table; PAHa, Predicted adult heightaccording to Baley-Pinneau's advanced table; FAH, final adult height; NS, not significant. "P<0.05 compared with FAH.

\section{Discussion}

Although previous studies have investigated puberty, growth, and FAH in SGA and AGA children, the present study remains significant as, to our knowledge, ${ }^{15-17)}$ it is the first to investigate the effects of GnRHa treatment in SGA and AGA patients with precocious puberty. In SGA individuals, growth in the first two years of life is very important, and most babies achieve catch-up growth with normal nutrition. However, $10 \%$ to $20 \%$ of SGA babies fail to achieve catch-up growth and may experience rapid increases in body weight due to excessive nutritional intake for catch-up growth. Such rapid increases in body weight promote insulin resistance, and SGA children also have decreased insulin-like growth factor (IGF) concentration and dysfunctional IGF metabolism, which place them at an endocrinological disadvantage. ${ }^{6)}$ Moreover, SGA children have a lower degree of insulin sensitivity relative to AGA children ${ }^{18)}$; it is known that high insulin concentrations stimulate $\mathrm{LH}$ secretion, inducing early pubertal growth. ${ }^{19)}$

A previous study concluded that SGA children reach puberty at almost appropriate ages but experience faster pubertal growth compared with AGA children and reported that their pubertal growth rate is faster relative to their short stature. ${ }^{15)}$ In other words, although both groups reached puberty at a similar age, the onset of puberty was earlier by 1 year on average in the SGA group than in the AGA group, and bone maturation progressed rapidly at earlier pubertal stages in the same.

Similarly, in this study, BA at the time of diagnosis of central precocious puberty was significantly advanced in the SGA group at $10.9 \pm 0.9$ years compared with in the AGA group at $10.3 \pm 0.8$ years. However, during and after GnRHa treatment, the two groups had similar BA and BA/CA ratio, confirming the effects of treatment on suppression of bone maturation in the SGA group.

In another previous study analyzing onset of puberty, onset of menarche, and FAH according to birth weight in 54 girls who showed breast development between the age of eight or

Table 3. Multiple regression analysis on final adult height

\begin{tabular}{lrc}
\hline Variable & $\beta$ & $P$-value \\
\hline At GnRHa treatment & & \\
TH & 0.247 & $<0.05$ \\
Height & -0.025 & 0.836 \\
Height SDS & 0.382 & $<0.05$ \\
PAH & -0.034 & 0.728 \\
PAHa & 0.288 & $<0.05$ \\
At 6months after GnRHa treatment & & \\
Height SDS & 0.561 & $<0.05$ \\
At end of GnRHa treatment & & \\
Height & 0.537 & $<0.05$ \\
Height SDS & 0.225 & $<0.05$ \\
\hline
\end{tabular}

GnRHa, gonadotropin-releasing hormone agonist; $T H$, target height; $\mathrm{PAH}$, predicted adult height-according to Baley-Pinneau's average table; $\mathrm{PAHa}$, Predicted adult height-according to Baley-Pinneau's advanced table; SDS, standard deviation score. 
nine years, the groups showed similar TH profiles. However, age at the onset of menarche was significantly younger in the SGA group at $11.3 \pm 0.3$ years than in the AGA group at $12.9 \pm 0.2$ years, while the FAH was smaller by $5 \mathrm{~cm}$ in the SGA group relative to in the AGA group. ${ }^{16)}$ Moreover, in 236 SGA girls and 281 AGA girls born at full term, the age at menarche did not differ significantly between $12.6 \pm 1.6$ years and $12.9 \pm 1.7$ years, respectively. Nevertheless, the FAH was significantly shorter by $3.9 \mathrm{~cm}$ in the SGA group than in the AGA group. ${ }^{17)}$

In the present study, the time between GnRHa treatment and menarche was $12.5 \pm 7.6$ months in the SGA group and $21.1 \pm 12.3$ months in the AGA group, a significant difference. These results indicate that early menarche in SGA children may be associated with early onset of puberty, which is generally observed in SGA children. However, in this study, the onset of menarche was noted after treatment for more than 30 months in $20 \%$ of the subjects in the AGA group; hence, the impact of this will need to be considered.

Compared with previous studies, the present investigation determined that the $\mathrm{TH}$ at the time of diagnosis of central precocious puberty was similar in the SGA and AGA groups; after GnRHa treatment, the FAH increased beyond the TH in both groups. In other words, the FAH was $161.0 \pm 4.7 \mathrm{~cm}$ in the SGA group and $161.6 \pm 5.0 \mathrm{~cm}$ in the AGA group, without any significant difference. This suggests that GnRHa is effective in increasing the FAH in both AGA and SGA children. GnRHa treatment is a standardized treatment for central precocious puberty, and the FAH is similar or improved relative to TH after treatment. ${ }^{4,5,20)}$ Similarly, in this study, the PAH was smaller than the TH at the time of diagnosis of central precocious puberty in all patients, but the PAH increased during treatment and ultimately exceeded the $\mathrm{TH}$ at the end of treatment.

When the BP average and advanced tables are used to calculate the PAH in central precocious puberty, the prediction made based on the BP advanced table may result in overestimation of normal child growth. It is known that measuring the $\mathrm{PAH}$ using the $\mathrm{BP}$ average table is more useful in patients who have not received GnRHa treatment, and the $\mathrm{BP}$ advanced table produces predictions closer to the FAH in patients receiving GnRHa treatment. ${ }^{21)}$ In addition, in this study, considering the relationships between FAH, PAH, and PAHa measured using the BP average and advanced tables, the FAH was close to the PAHa measured using the advanced table.

This study investigated the clinical significance of GnRHa treatment in girls with central precocious puberty according to birth weight. SGA patients may show early bone maturity and puberty; thus, their FAH may be lower than that in the AGA group. However, in this study, we confirmed the effects of bone maturity suppression on SGA in CPP, and that the FAH showed a greater increase than the TH.

This study has some limitations. Since this study had a small sample size, the significance of clinical variables after GnRHa treatment and FAH according to birth weight in girls with central precocious puberty should be investigated further in larger groups with longer-term follow-up. Moreover, this study used the standard pediatric growth table published by the Korean Pediatric Society in 2007, but a revised version of the table was published in 2017 that may yield slightly different outcomes. Further research can be conducted using the standard deviation in physical development presented in the new table published in 2017, and the results can subsequently be compared.

\section{Ethical statement}

This study was approved by the Institutional Review Board (No. 2019-02-004-003) of Chosun University Hospital. This study was retrospective and was, therefore, exempted from need for informed consent.

\section{Conflict of interest}

No potential conflict of interest relevant to this article was reported.

\section{Acknowledgments}

This study was supported by a research fund received from Chosun University Hospital in 2017.

\section{References}

1. Carel JC, Léger J. Clinical practice. Precocious puberty. N Engl J Med 2008;358:2366-77.

2. Bertelloni S, Baroncelli GI, Sorrentino MC, Perri G, Saggese G. Effect of central precocious puberty and gonadotropinreleasing hormone analogue treatment on peak bone mass and final height in females. Eur J Pediatr 1998;157:363-7.

3. Lahlou N, Carel JC, Chaussain JL, Roger M. Pharmacokinetics and pharmacodynamics of GnRH agonists: clinical implications in pediatrics. J Pediatr Endocrinol Metab 2000;13 Suppl 1:723-37.

4. Jung MK, Song KC, Kwon AR, Chae HW, Kim DH, Kim HS. Adult height in girls with central precocious puberty treated with gonadotropin-releasing hormone agonist with or without growth hormone. Ann Pediatr Endocrinol Metab 2014;19:214-9.

5. Ying Y, Tang J, Chen W, Cai Z, Niu WT. GnRH agonist treatment for idiopathic central precocious puberty can improve final adult height in Chinese girls. Oncotarget 2017;8:109061-7.

6. Kim SY. Growth and sex differentiation of children born small for gestational age. Korean J Pediatr 2009;52:142-51.

7. Albertsson-Wikland K. Growth hormone treatment in short children. Acta Paediatr Scand Suppl 1986;325:64-70.

8. Hokken-Koelega AC, De Ridder MA, Lemmen RJ, Den Hartog H, De Muinck Keizer-Schrama SM, Drop SL. Children born small for gestational age: do they catch up? 
Pediatr Res 1995;38:267-71.

9. Ibáñez L, Jiménez R, de Zegher F. Early puberty-menarche after precocious pubarche: relation to prenatal growth. Pediatrics 2006;117:117-21.

10. Persson I, Ahlsson F, Ewald U, Tuvemo T, Qingyuan M, von Rosen D, et al. Influence of perinatal factors on the onset of puberty in boys and girls: implications for interpretation of link with risk of long term diseases. Am J Epidemiol 1999;150:747-55.

11. Hernández MI, Martínez A, Capurro T, Peña V, Trejo L, Avila A, et al. Comparison of clinical, ultrasonographic, and biochemical differences at the beginning of puberty in healthy girls born either small for gestational age or appropriate for gestational age: preliminary results. J Clin Endocrinol Metab 2006;91:3377-81.

12. Veening MA, van Weissenbruch MM, Roord JJ, de Delemarre-van Waal HA. Pubertal development in children born small for gestational age. J Pediatr Endocrinol Metab 2004;17:1497-505.

13. Greulich WW, Pyle SI. Radiographic atlas of skeletal development of the hand and wrist. 2nd ed. Stanford (CA): Stanford University Press, 1971.

14. Bayley N, Pinneau SR. Tables for predicting adult height from skeletal age: revised for use with the Greulich-Pyle hand standards. J Pediatr 1952;40:423-41.

15. Lazar L, Pollak U, Kalter-Leibovici O, Pertzelan A, Phillip M. Pubertal course of persistently short children born small for gestational age (SGA) compared with idiopathic short children born appropriate for gestational age (AGA). Eur J Endocrinol 2003;149:425-32.

16. Ibáñez L, Ferrer A, Marcos MV, Hierro FR, de Zegher F. Early puberty: rapid progression and reduced final height in girls with low birth weight. Pediatrics 2000;106:E72.

17. Hernández MI, Mericq V. Pubertal development in girls born small for gestational age. J Pediatr Endocrinol Metab 2008;21:201-8.

18. Hofman PL, Cutfield WS, Robinson EM, Bergman RN, Menon RK, Sperling MA, et al. Insulin resistance in short children with intrauterine growth retardation. J Clin Endocrinol Metab 1997;82:402-6.

19. Cara JF, Rosenfield RL. Insulin-like growth factor I and insulin potentiate luteinizing hormone-induced androgen synthesis by rat ovarian thecal-interstitial cells. Endocrinology 1988;123:733-9.

20. Lee HS, Yoon JS, Park KJ, Hwang JS. Increased final adult height by gonadotropin-releasing hormone agonist in girls with idiopathic central precocious puberty. PLoS One 2018;13:e0201906.

21. Tanaka T, Niimi H, Matsuo N, Fujieda K, Tachibana K, Ohyama K, et al. Results of long-term follow-up after treatment of central precocious puberty with leuprorelin acetate: evaluation of effectiveness of treatment and recovery of gonadal function. The TAP-144-SR Japanese Study Group on Central Precocious Puberty. J Clin Endocrinol Metab 2005;90:1371-6. 